\title{
Treatment with Methanol Root Extract of Mirabilis jalapa Suppresses Postprandial Hyperglycemia and Dyslipidemia in Diabetic Rats
}

\author{
*M.E. Sadiq, A.L. Abubakar, H.Y. Abubakar and H. Adio \\ Department of Biochemistry, Usmanu Danfodiyo University, Sokoto, Nigeria \\ [ ${ }^{\star}$ Corresponding Author: E-mail: sadiq.masud@udusok.edu.ng; : : +2348026917014]
}

\section{ABSTRACT}

The present study demonstrates the postprandial hypoglycemic effects of methanol root extract of Mirabilis jalapa. Alloxan induced diabetic rats were treated with $200 \mathrm{mg} / \mathrm{kg}$ body weight of the extract for 9 days at 12 hourly intervals. The experiment was designed to assess both fasting and 2 hour postprandial blood glucose levels. Lipid profile and liver function biochemical analyses were conducted using serum obtained from the experimental animals sacrificed after 10 days. The results showed a marked difference in blood glucose levels postprandial in the diabetic group treated with the extract (DTM) $(11.02 \pm 1.42 \mathrm{mmo} / \mathrm{L})$ when compared with the diabetic untreated group (DU) $(19.80 \pm 5.37 \mathrm{mmol} / \mathrm{L})$. Similar trends were observed for the fasting blood glucose which remained elevated in the DU group throughout the experiment but was maintained at comparable levels $(4.70-6.82 \mathrm{mmol} / \mathrm{L})$ between healthy control group (HU) and all other groups treated both with extract and standard drug metformin. Triglyceride levels of diabetic groups treated with the extract were also observed to fall within comparable limits with the HU group ( $30.79 \pm 4.76$ $-65.95 \pm 2.42 \mathrm{mg} / \mathrm{L}$ ). In conclusion, treatment with methanol root extract of Mirabilis jalapa suppresses hyperglycemia postprandial and probably promotes slow progression to dyslipidemia in experimentally induced diabetes in rats.

Keywords: Mirabilis jalapa, Diabetes mellitus, Hypoglycemia, metformin

\section{INTRODUCTION}

The global prevalence of diabetes has been on a steady rise since 1980s. By 2014, an estimated 422 million adults were living with the disease (WHO, 2016). This figure is projected to rise to 592 million by 2035 (Guariguata et al., 2014). Recent findings indicates an alarming trend of diabetes (about $8.6 \%$ prevalence) in low-middle income countries (LIMC) most of whom live in rural areas (Hwang et al., 2012; Zebetian et al., 2014). According to Ogurtsova et al. (2017), $75 \%$ of people living with diabetes live in low and middle income countries and this region (Afirca and Middle East) is projected to experience high growth in people living with diabetes $(140.7 \%$ increase by 2040).

Rural populations especially in African communities depend on medicinal plants for treatment of various ailments. Preparations of medicinal plants either as extractives or as part of dietary recipe in the treatment of diabetes mellitus are common practice in different ethnic groups in Nigeria (Ezuruike and Prieto, 2014). Among other reasons such as cultural beliefs, poor accessibility, scarcity and cost of prescription drugs, overstretched health care facilities in these communities are common factors that influence the resort to alternative means for treatment. Most often than not, medicinal plants are considered the solution to this problem.

Mirabilis jalapa commonly known as "four o'clock" plant (Holdsworth, 1992) and locally as tonaposo in Yoruba language (Elufioye et al., 2012) belongs to the family Nyctaginaceae. It is commonly used in Chinese folk medicine to treat diabetes (Zhou et al., 2012a), constipation (Lee et al., 2008), genitourinary system disorder and injuries (Weckerle et al., 2009). It is also widely used to treat dysentery, diarrhea (Sadiq et al., 2016) muscular pain, and abdominal colics (Walker et al., 2008). Its extract has antibacterial 
(Eneji et al., 2011) antiviral, and antifungal functions (Vivanco et al., 1999). This study examines the hypoglycemic and antidyslipidemic effects of oral administration of root extracts of the plant in alloxan induced hyperglycemic rats as compared to treatment with metformin.

\section{MATERIALS AND METHODS Materials}

All chemicals and reagents used were as follows: absolute methanol (Sigma Aldrich, USA), test kits for lipid profile and liver function tests (Randox, Northern Ireland). The chemical alloxan monohydrate was kindly donated by the Department of Biochemistry, Usmanu Danfodiyo University, Sokoto. A glucometer (Finetest, model number IGM-0017B, Infopia Co Itd, Korea) was used for blood glucose tests. Equipment used included rotary evaporator (Cole-parmer 115VAC), spectrophotometer (AMEX SQ2800), centrifuge (110V desktop electric) and drying chamber.

\section{Plant Material}

The whole plant M. jalapa was obtained from Igabi local government area, Kaduna State and identified by a botanist at the Herbarium of the Department of Biological Sciences, Ahmadu Bello University, Zaria with a specimen voucher number 2441. The roots were cut into small pieces, dried (under shade) to a constant dry weight, subsequently grinded using pestle and mortar and stored until required.

\section{Experimental Animals}

Twenty-five (25) wistar albino rats weighing between $0.14-0.22 \mathrm{~kg}$ were used for this study. The animals were obtained from Abraham farms, Kaduna and transported to the animal house of Department of Biochemistry, Faculty of Science, Usmanu Danfodiyo University (UDU), Sokoto. In accordance with the Approval and guidelines of the ethical committee, Department of Biochemistry, UDU, Sokoto, the animals were housed in well ventilated plastic cages at $25^{\circ} \mathrm{C}$ and were fed with pelleted growers feed (Vital feeds, UAC foods) and water ad libitum prior to experimentation. The rats were allowed to acclimatize for two weeks.

\section{METHODOLOGY}

\section{Plant Material Extraction}

Exactly $1 \mathrm{~kg}$ of ground $M$. jalapa root was macerated in 4 litres of absolute methanol and left in an air tight aspirator bottle for 72 hours. The preparation was filtered first using muslin cloth then Whatmann filter paper number 1 . The filtrate was concentrated with the aid of a rotary evaporator and drying cabinet set at $45^{\circ} \mathrm{C}$. The concentrated extract was kept in a $\mathrm{CaCl}_{2}$ containing desiccator.

\section{Experimental Design}

After acclimatization, the animals were grouped according to their body weights into five groups of five animals per group and were labeled as follows: Group 1: diabetic untreated rats (DU); Group 2: healthy untreated rats (HU); Group 3: diabetic rats treated with $M$. jalapa methanol extract (DTM); Group 4: diabetic rats treated with standard drug metformin (DTS); Group 5: healthy rats treated with $M$. jalapa methanol extract (HTM). Hyperglycemia was induced in the groups DU, DTM and DTS by subcutaneous administration of alloxan monohydrate at a dose of $100 \mathrm{mg} / \mathrm{kg}$ body weight per day for three days. The animals were given glucose solution to prevent hypoglycemia. The procedure was repeated until hyperglycemia was confirmed using a glucometer strip test. Animals with fasting blood glucose levels (FBS) $>11.0 \mathrm{mmol} / \mathrm{L}$ were considered hyperglycemic and were included in the study.

\section{Treatment of Experimental Animals}

The experimental animals were treated with a dose of $200 \mathrm{mg} / \mathrm{kg}$ body weight administered orally at 12 hourly intervals (12am and $12 \mathrm{pm}$ ) for 9 days. The rats were fasted for 6 hours ( 12 am- 6 am); after which blood samples were collected from the tail for measurement of fasting blood sugar levels using a glucometer. The animals were then allowed access to feed for 2 hours and blood glucose measurement was again taken. 
The animals were humanely sacrificed on day 10 , blood samples collected in heparinized tubes, centrifuged at 4000rpm and serum obtained was used for assessment of lipid profile and liver function biochemical parameters according to manufacturer's procedure described in purchased test kits.

\section{Statistical Analysis}

All data were expressed as mean \pm standard deviation. Student T-test was used to compare treatments $(p<0.05)$ while differences in group treatments was analyzed by one-way analysis of variance (ANOVA) with tukey post-hoc test using instant 3 software $\quad(p<0.05)$. Spearman's Correlation was conducted to show relationship between blood glucose and lipid profile as influenced by treatments administered.

\section{RESULTS}

Table 1 shows the Fasting Blood Glucose (FBG) levels of experimental animals treated with methanol root extracts of M. jalapa. The untreated diabetic group (DU) had a sustained hyperglycemia throughout the experimental period. No significant difference $(p<0.05)$ in the blood glucose levels of the treated diabetic groups DTM and DTS when compared with the untreated diabetic group (DU) on day 1 (before treatment). By day 4 however, a significant drop in fasting blood glucose $(5.46 \pm 0.04 \mathrm{mmol} / \mathrm{L})$ was observed in the DTM group which was not significantly different $(p>0.05)$ from the healthy control groups (HU and HTM). Results of 2 hour postprandial (2HPP) blood glucose show that treatment with methanol root extract of the plant significantly lowered $(p<0.05)$ blood glucose levels postprandial as treatment progressed. The values recorded for the diabetic treated group DTM $(8.60 \pm 2.20 \mathrm{mmol} / \mathrm{L})$ compared with that observed for the healthy treated group $(5.78 \pm 0.39 \mathrm{mmol} / \mathrm{L})$ as at day 10 .

Differences in average values of FBG and 2HPP treatments on days 4 and 7 (Figure 1) were significant $(p<0.05)$ in diabetic animals (DTM) treated with the extract. The untreated diabetic group (DU) however had elevated blood sugar levels for both treatments throughout the experimental period $(p>0.05)$.

Table 1: Effect of oral administration of methanol extracts of Mirabilis jalapa roots on fasting blood sugar (FBS) levels of experimental animals.

\section{FBS (mmol/L)}

\begin{tabular}{clllll}
\hline Groups & $\begin{array}{l}\text { Before } \\
\text { alloxan } \\
\text { induction }\end{array}$ & $\begin{array}{l}\text { Day 1 } \\
\text { (No treatment) }\end{array}$ & Day 4 & Day 7 & Day 10 \\
\hline DU & $5.30 \pm 0.65^{\mathrm{a}}$ & $15.90 \pm 2.45^{\mathrm{a}}$ & $15.10 \pm 1.37^{\mathrm{b}}$ & $15.40 \pm 4.74^{\mathrm{a}}$ & $10.42 \pm 2.97^{\mathrm{b}}$ \\
HU & $5.34 \pm 0.63^{\mathrm{a}}$ & $5.34 \pm 0.63^{\mathrm{b}}$ & $5.00 \pm 0.98^{\mathrm{a}}$ & $4.78 \pm 0.47 \mathrm{~b}$ & $4.70 \pm 0.36^{\mathrm{a}}$ \\
HTM & $5.10 \pm 0.60^{\mathrm{a}}$ & $5.10 \pm 0.60^{\mathrm{b}}$ & $3.32 \pm 1.06^{\mathrm{a}}$ & $5.60 \pm 0.26^{\mathrm{b}}$ & $4.98 \pm 0.13^{\mathrm{a}}$ \\
DTM & $6.50 \pm 0.17^{\mathrm{a}}$ & $15.60 \pm 3.81^{\mathrm{a}}$ & $5.46 \pm 0.40^{\mathrm{a}}$ & $6.62 \pm 1.10^{\mathrm{b}}$ & $6.28 \pm 1.29^{\mathrm{a}}$ \\
DTS & $6.02 \pm 0.39^{\mathrm{a}}$ & $19.60 \pm 4.34^{\mathrm{a}}$ & $13.78 \pm 4.53^{\mathrm{b}}$ & $11.80 \pm 3.28^{\mathrm{a}}$ & $6.82 \pm 0.40^{\mathrm{a}}$ \\
\hline
\end{tabular}

Data are expressed as mean \pm standard deviation, $n=5$. Values bearing different superscript within a particular column differ significantly $(\mathrm{p}<0.05)$.

Key: DU: Diabetic untreated rats (diabetic control); HU: Healthy untreated rats (normal control); HTM: Healthy rats treated with M. jalapa extract; DTM: Diabetic treated with M. jalapa extract; DTS: Diabetic treated with standard drug. 
Table 2: Effect of oral administration of methanolic extracts of Mirabilis jalapa L. roots on 2 hours postprandial blood glucose (2HPP) of experimental rats.

$$
\text { 2HPP(mmol/L) }
$$

\begin{tabular}{clllll}
\hline Groups & $\begin{array}{l}\text { Before alloxan } \\
\text { induction }\end{array}$ & $\begin{array}{l}\text { Day 1 } \\
\text { (No treatment) }\end{array}$ & Day 4 & Day 7 & Day 10 \\
\hline DU & $5.30 \pm 0.65$ & $15.90 \pm 2.45^{\mathrm{a}}$ & $17.62 \pm 2.82^{\mathrm{a}}$ & $19.80 \pm 5.37^{\mathrm{a}}$ & $24.24 \pm 2.96^{\mathrm{a}}$ \\
HU & $5.34 \pm 0.63$ & $5.34 \pm 0.63^{\mathrm{b}}$ & $6.00 \pm 0.50^{\mathrm{b}}$ & $5.96 \pm 0.27^{\mathrm{b}}$ & $5.88 \pm 0.14^{\mathrm{b}}$ \\
HTM & $5.10 \pm 0.60$ & $5.10 \pm 0.60^{\mathrm{b}}$ & $6.38 \pm 1.46^{\mathrm{b}}$ & $6.28 \pm 0.10^{\mathrm{b}}$ & $5.78 \pm 0.39^{\mathrm{b}}$ \\
DTM & $6.50 \pm 0.17$ & $15.60 \pm 3.81^{\mathrm{a}}$ & $12.36 \pm 1.43^{\mathrm{a}, \mathrm{b}}$ & $11.02 \pm 1.42^{\mathrm{b}, \mathrm{c}}$ & $8.60 \pm 2.20^{\mathrm{b}, \mathrm{d}}$ \\
DTS & $6.02 \pm 0.39$ & $19.60 \pm 4.34^{\mathrm{a}}$ & $18.10 \pm 4.08^{\mathrm{a}}$ & $14.24 \pm 3.12^{\mathrm{a}, \mathrm{c}}$ & $12.26 \pm 3.93^{\mathrm{c}, \mathrm{d}}$ \\
\hline
\end{tabular}

Data are expressed as mean \pm standard deviation, $n=5$. Values bearing different superscript within a particular column differ significantly $(\mathrm{p}<0.05)$

Key: DU: Diabetic untreated rats (diabetic control); HU: Healthy untreated rats (normal control); HTM: Healthy rats treated with M. jalapa extract; DTM: Diabetic treated with M. jalapa extract; DTS: Diabetic treated with standard drug

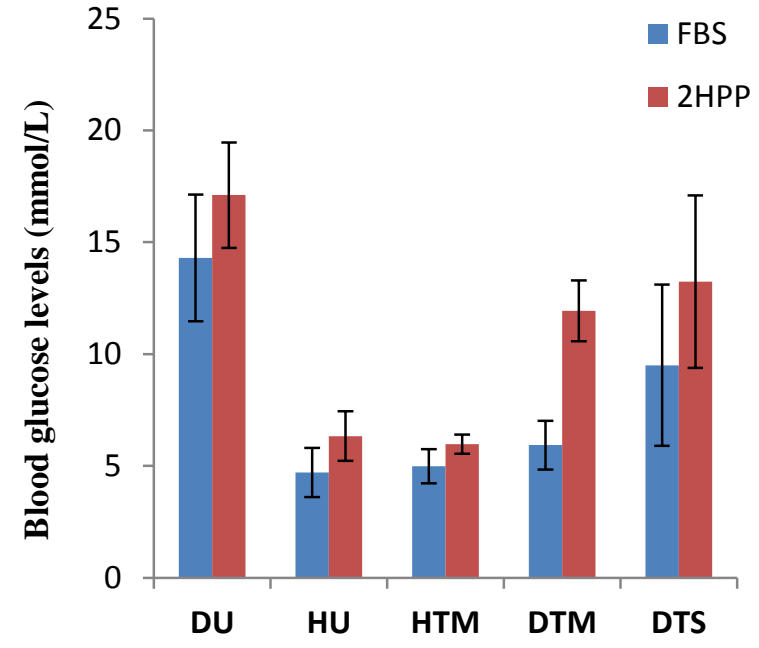

Figure 1: Comparison of FBS and 2HPP of experimental rats treated with methanol extracts of Mirabilis jalapa L. roots.

Key: DU: Diabetic untreated rats (diabetic control); HU: Healthy untreated rats (normal control); HTM: Healthy rats treated with M. jalapa extract; DTM: Diabetic treated with M. jalapa extract; DTS: Diabetic treated with standard drug metformin

Effects of administration of methanol root extract of the plant on indices of liver function indicated an elevation in total proteins in the diabetic untreated (DU) and all treated groups (HTM, DTM and DTS) in the range $42.36 \pm 3.10-$
$43.74 \pm 2.67 \mathrm{~g} / \mathrm{dL}$ when compared with the healthy control group HU $(21.93 \pm 4.60 \mathrm{~g} / \mathrm{dL})$. Although albumin levels in all the groups were comparable, the AST and ALT levels in the DTM group were significantly different $(p<0.05)$ from values observed for the DU and DTS groups (Table 3 )

The lipid profile of experimental animals (Figure 2) shows the total glyceride levels (TAG) of treated groups DTM and DTS were significantly different $(p<0.05)$ from the diabetic untreated group (DU). A similar trend was observed for the VLDL-C levels, where values observed for DTS and DTM were between $13.15 \pm 0.49$ and $15.72 \pm 0.63 \mathrm{mg} / \mathrm{dL}$ as compared to $25.11 \pm 0.27$ $\mathrm{mg} / \mathrm{dL}$ recorded for the diabetic untreated group. A significant difference $(p<0.05)$ was also observed for HDL-C levels between the diabetic untreated group and treated diabetic groups but HDL-C levels of treated diabetic groups were comparable to the healthy untreated groups (Figure 2). Fasting blood sugar levels (FBG) and lipid profiles were strongly correlated in the diabetic untreated group (DU) while FBG values of the methanol root extract treated group (DTM) correlated negatively with TC, TAG and VLDL-C $(-0.65,-0.14$ and -0.18$)$ respectively (Table 4$)$. 
Table 3: Effect of oral administration of methanolic extract of $M$. jalapa roots on liver biochemical indices of experimental rats.

\begin{tabular}{ccccc}
\hline Groups & TP $(\mathbf{g} / \mathrm{dL})$ & Albumin $(\mathrm{g} / \mathrm{dL})$ & ALT $(\mathrm{U} / \mathrm{I})$ & AST $(\mathrm{U} / \mathrm{I})$ \\
\hline DU & $43.74 \pm 2.67^{\mathrm{a}}$ & $2.35 \pm 0.20^{\mathrm{ab}}$ & $43.63 \pm 3.2^{\mathrm{a}}$ & $149.62 \pm 4.1^{\mathrm{a}}$ \\
HU & $21.93 \pm 4.60^{\mathrm{b}}$ & $2.17 \pm 0.07^{\mathrm{b}}$ & $12.00 \pm 1.41^{\mathrm{b}}$ & $124.41 \pm 8.79^{\mathrm{b}}$ \\
HTM & $46.09 \pm 6.35^{\mathrm{a}}$ & $2.27 \pm 0.05^{\mathrm{b}}$ & $15.83 \pm 2.86^{\mathrm{b}}$ & $134.80 \pm 4.45^{\mathrm{b}}$ \\
DTM & $39.04 \pm 4.39^{\mathrm{a}}$ & $2.29 \pm 0.06^{\mathrm{b}}$ & $26.75 \pm 5.32^{\mathrm{c}}$ & $125.45 \pm 1.54^{\mathrm{b}}$ \\
DTS & $42.36 \pm 3.10^{\mathrm{a}}$ & $2.57 \pm 0.11^{\mathrm{a}}$ & $43.00 \pm 0.82^{\mathrm{a}}$ & $150.89 \pm 2.95^{\mathrm{a}}$ \\
\hline
\end{tabular}

Data are expressed as mean \pm standard deviation, $n=5$. Values bearing the same superscript within a particular column do not differ significantly $(P>0.05)$ while values bearing different superscript within a particular column differ significantly $(p<0.05)$.

Key: DU: Diabetic untreated rats (diabetic control); HU: Healthy untreated rats (normal control); HTM: Healthy rats treated with M. jalapa extract; DTM: Diabetic treated with M. jalapa extract; DTS: Diabetic treated with standard drug

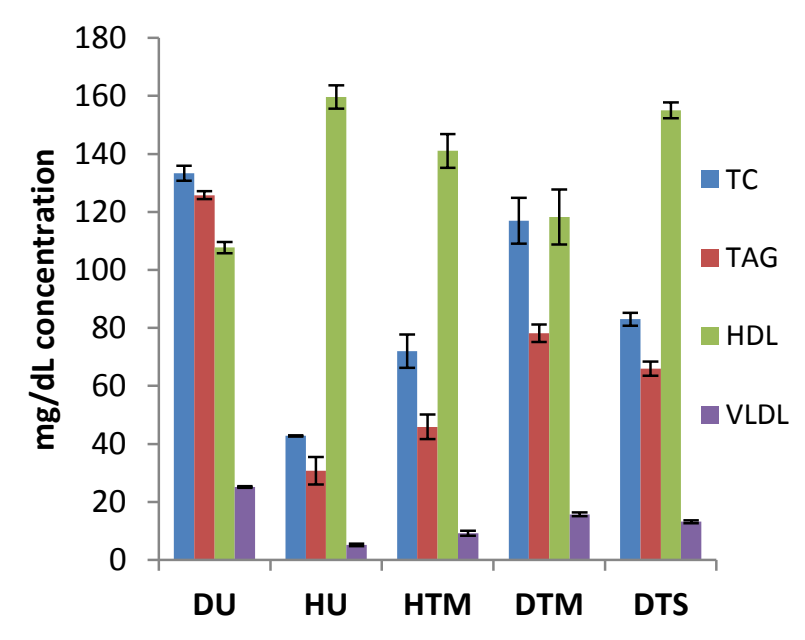

Figure 2: Lipid profile parameters of experimental animals treated with methanol root extracts of M. jalapa

Key: DU: Diabetic untreated rats (diabetic control); HU: Healthy untreated rats (normal control); HTM: Healthy rats treated with M. jalapa extract; DTM: Diabetic treated with M. jalapa extract; DTS: Diabetic treated with standard drug

\section{DISCUSSION}

A sustained hyperglycemic state has long been recognized as underlying cause of chronic disturbances often seen in diabetes. The mobilization of fuel molecules to compensate for energy charge in insulin dependent cells signals failure in transport processes involved in cellular uptake of glucose. In response, cellular dynamics shift in favor of anabolic pathways leading to biosynthesis of glucose which complicates further, the blood glucose threshold. As demonstrated in this study, the methanol root extract of $M$. jalapa showed a blood glucose lowering effect (Table 1). A progression towards euglycemic state was observed following treatment with $200 \mathrm{mg} / \mathrm{Kg}$ body weight of the extract. The blood glucose lowering mechanism most probably differs from that observed for the standard drug metformin as shown in Table 2, where postprandial glucose remained elevated $(12.26 \pm 3.93 \mathrm{mmol} / \mathrm{L})$ in the diabetic group treated with metformin compared with that observed for diabetic group treated with the extract ( DTM = $8.60 \pm 2.20 \mathrm{mmol} / \mathrm{L})$ as at Day 10 . Oral hypoglycemics lower blood glucose by different mechanisms (Bosenberg and Van Zyl, 2008). Metformin requires residual insulin activity but has minimal effect on postprandial glucose (Lund et al., 2009). Zhou et al. (2012b) demonstrated ethanolic extract of $M$. jalapa roots had hypoglycemic and hypolipidemic effects in streptozotocin induced diabetes in mice and suggested further the compound trigonelline 
present in the root of the plant most probably contributes to the observed effects (Zhou et al., 2013). It was proposed that trigonelline influenced the GLP-1 receptor/p38 mitogen activated protein kinases signaling pathway (Zhou and Zhou, 2012b). The DPP4 and aglucosidase inhibitory potentials of this compound in both plasma and small intestine have also been reported (Hamden et al., 2013). The regulatory effects of the extract on postprandial glucose as demonstrated in this study support the insulinotropic and/or DPP4 inhibitory mechanisms, both of which are important in down regulating glucagon release. These mechanisms appear to be beneficial to diabetics with residual insulin activity which is typical of type 2 diabetes mellitus. Differences in the glucose levels postprandial (Table 2) and the observed marked difference $(p<0.05)$ between FBS and 2HPP (Figure 1) for all the groups except the diabetic untreated group (DU) suggests a mechanism of action of the extract different from that of metformin. The extract may have a stimulatory activity for insulin or enhance secretion or prolong the activity of GLP-1 peptide (Zhou et al., 2012b).

One of the actions of the hormone glucagon is the stimulation of lipolysis as a carbon source in gluconeogenesis. The observed drop in TAGs of diabetic group treated with the extract $(78.18$ $\mathrm{mg} / \mathrm{dL}$ ) when compared with untreated diabetic group (125.76 mg/dL) suggest an extract activity that promotes glucose utilization in meeting the energy needs of insulin dependent cells. FBS versus TAG and VLDL-C were observed to correlate negatively (Table 4). According to Khan et al. (2007), FBS exhibits a direct positive correlation with TC, TG, and VLDL but inverse $\mathrm{HDL}$ in diabetics. Similarly, a negative correlation of -0.14 (Table 4) between FBS and triglycerides indicates improvements in fuel molecule utilization thereby down regulating the need for lipolysis hence minimal TAGs mobilization. FBS of diabetic (DU) and healthy (HU) groups correlated positively with TGs, HDL and VLDL (Table 4). However, the correlation was stronger in the DU group due to derangements in hormonal regulatory mechanisms. Healthy animals are better able to regulate energy balance depending on metabolic needs. Although not demonstrated in this study, it is however evident that glucose uptake may play a role in the slow progression to dyslipidemia as observed in diabetic group treated with methanol root extract of $M$. jalapa suggestive of a balanced ATP : ADP ratio of individual insulin dependent cells.

Table 4: Correlation of effect oral administration of methanol extract of $M$. jalapa roots on FBS and Lipid profile of experimental animals

\begin{tabular}{lcccc}
\hline GROUPS & TC & TAG & HDL-C & VLDL-C \\
\hline DU & 0.81 & 0.83 & 0.86 & 0.84 \\
HU & -0.13 & 0.23 & 0.69 & 0.47 \\
HTM & 0.53 & 0.95 & -0.32 & 0.96 \\
DTM & -0.65 & -0.14 & 0.46 & -0.13 \\
DTS & -0.10 & 0.40 & -0.02 & 0.31 \\
\hline
\end{tabular}

Key: DU: Diabetic untreated rats (diabetic control); HU: Healthy untreated rats (normal control); HTM: Healthy rats treated with M. jalapa extract; DTM: Diabetic treated with M. jalapa extract; DTS: Diabetic treated with standard drug 


\section{Nigerian Journal of Basic and Applied Science (December, 2018), 26(2): 59-66}

\section{CONCLUSION}

Normo-glycemia and a generally slow progression to dyslipidemia were influenced by administration of Mirabilis jalapa root methanol extract to alloxan induced diabetic rats. The plant was also demonstrated to have postprandial hypoglycemic effect with a possible mechanism different from that of the standard drug metformin.

\section{ACKNOWLEDGEMENT}

We are grateful to the Department of Biochemistry, UDU, Sokoto for providing space in the animal house and supply of some reagents/chemicals for this research.

FUNDING: Self sponsorship

CONFLICT OF INTEREST: The authors declare no conflict of interest

\section{REFERENCES}

Bosenberg, L.H. and Van Zyl, D.G. (2008). The mechanism of action of oral antidiabetic drugs. Journal of Endocrinology, Metabolism and Diabetes of South Africa, 13(3): 80-88.

Elufioye T.O., Oladele AT, Cyril-Olutayo CM, Agbedahunsi JM, Adesanya SA (2012). Ethnomedicinal study and screening of plants used for memory enhancement and antiaging in Sagamu, Nigeria. European Journal of Medicinal Plants, 2(3):262.

Eneji, S.M., Inuwa, H.M., Ibrahim, S., Ibrahim, A.B. and Abdulfattah, A. (2011). In vitro assessment of bioactive components of Mirabilis jalapa ethanolic extract on clinical isolates of Salmonella typhi and Bacillus cereus. African Journal of Biotechnology, 10(71):16006-16011.

Ezuruike, U. F. and Prieto, J. M. (2014). The use of plants in the traditional management of diabetes in Nigeria: Pharmacological and toxicological considerations. Journal of Ethnopharmacology, 155(2), 857-924.
Guariguata, L., Whiting, D. R., Hambleton, I., Beagley, J., Linnenkamp, U., \& Shaw, J. E. (2014). Global estimates of diabetes prevalence for 2013 and projections for 2035. Diabetes research and clinical practice, 103(2), 137-149.

Hamden, K., Bengara, A., Amri, Z., and Elfeki, A. (2013). Experimental diabetes treated with trigonelline: effect on key enzymes related to diabetes and hypertension, $\beta$ cell and liver function. Molecular and Cellular Biochemistry, 381(1-2), 85-94.

Holdsworth, D.K. (1992). A preliminary study of medicinal plants of Easter Island, South Pacific. International Journal Pharmacognosy, 30:27-32.

Hwang, C. K., Han, P. V., Zabetian, A., Ali, M. K., \& Narayan, K. V. (2012). Rural diabetes prevalence quintuples over twenty-five years in low-and middle-income countries: a systematic review and metaanalysis. Diabetes Research and Clinical Practice, 96(3), 271-285.

Khan, H. A., Sobki, S. H., \& Khan, S. A. (2007). Association between glycaemic control and serum lipids profile in type 2 diabetic patients: $\mathrm{HbA}$ 1c predicts dyslipidaemia. Clinical and Experimental Medicine, 7(1), 24-29.

Lee, S., Xiao, C. and Pei, S. (2008). Ethnobotanical survey of medicinal plants at periodic markets of Honghe Prefecture in Yunnan Province, SW China. Journal of Ethnopharmacology, 117(2), 362-377.

Lund, S. S., Tarnow, L., Frandsen, M., Nielsen, B. B., Hansen, B. V., Pedersen, O., ... \& Vaag, A. A. (2009). Combining insulin with metformin or an insulin secretagogue in non-obese patients with type 2 diabetes: 12 month, randomised, double blind trial. BMJ, 339, b4324.

Ogurtsova, K., da Rocha Fernandes, J. D., Huang, Y., Linnenkamp, U., Guariguata, L., Cho, N. H., ... \& Makaroff, L. E. (2017). IDF Diabetes Atlas: Global estimates for the prevalence of diabetes 


\section{Sadiq et al: Treatment with Methanol Root Extract of Mirabilis jalapa Suppresses.}

for 2015 and 2040. Diabetes research and clinical practice, 128, 40-50.

Sadiq, M.E., Inuwa, H.M., Mujeeb-ur-Rehman and Ahmad, K. (2016). In silico physicochemical evaluation, anti-inflammatory and mcf-7 breast cancer cell line growth inhibition effects of trolline isolated from Mirabilis jalapa. Journal of Medicinal Plants Research, 10(42), 783-789.

Vivanco, J.M., Querci, M., and Salazar, L.F. (1999). Antiviral and antiviroid activity of MAP-containing extract from Mirabilis jalapa roots. Plant Disease, 83(12):1116-1121

Walker, C.I.B., Trevisan, G., Rossato, M.F., Franciscato, C., Pereira, M.E., Ferreira, J., and Manfron, M.P. (2008). Antinociceptive activity of Mirabilis jalapa in mice. Journal of Ethnopharmacology, 120(2):169-175.

Weckerle, C. S., Ineichen, R., Huber, F. K., \& Yang, Y. (2009). Mao's heritage: Medicinal plant knowledge among the Bai in Shaxi, China, at a crossroads between distinct local and common widespread practice. Journal of Ethnopharmacology, 123(2), 213-228.

World Health Organization. (2016). Global report on diabetes. World Health Organization.
Zabetian, A., Sanchez, I.M., Narayan, K.V., Hwang, C.K., \& Ali, M.K. (2014). Global rural diabetes prevalence: a systematic review and meta-analysis covering 1990-2012. Diabetes research and clinical practice, 104(2), 206-213.

Zhou, J., Chan, L. and Zhou, S. (2012a). Trigonelline: a plant alkaloid with therapeutic potential for diabetes and central nervous system disease. Current Medicinal Chemistry, 19(21), 3523-3531.

Zhou, J. Y., Zhou, S. W., Zeng, S. Y., Zhou, J. Y., Jiang, M. J., and He, Y. (2012b). Hypoglycemic and hypolipidemic effects of ethanolic extract of Mirabilis jalapa $L$. root on normal and diabetic mice. Evidence-Based Complementary and Alternative Medicine, 2012: 257374

Zhou, J., Zhou, S. and Zeng, S. (2013), Experimental diabetes treated with trigonelline: effect on $\beta$ cell and pancreatic oxidative parameters. Fundamental and Clinical Pharmacology, 27, 279-287. 